\title{
Serviços via Web em bibliotecas universitárias \\ brasileiras
}

Carlos Henrique Marcondes

Mestre e Doutor em Ciência da Informação, professor do Depto. de Ciência

da Informaçãa e do Programa de Pós-graduação em Ciência da Informação

- PPGCI- IBICT/UFF

Marilia A. Mendonça

Mestre em Administração de Sistemas de Informação, professora do Depto.

de Ciência da Informação/UFF

Suzana M. Carvalho

Aluna do Curso de Biblioteconomia e Docmentação/UFF, bolsista de

Iniciação Científica

Resultados de pesquisa apoiada pelo PIBIC CNPq/UFF, desenvolvida no período agosto/2004 a julho/2005, com o objetivo de identificar a existência de serviços oferecidos via web em bibliotecas universitárias brasileiras. Foram avaliadas as páginas de 209 bibliotecas universitárias de todas as regiões geográficas do país, tendo como critério de seleção as universidades com maior número de cursos de pós-graduação, segundo o site da CAPES, considerandose as sete primeiras universidades de cada região. Os sites das bibliotecas destas universidades foram visitados e avaliados, com objetivo de identificar os tipos de serviços oferecidos via web. Verificou-se que este tipo de serviço ainda é pouco oferecido pelas bibliotecas universitárias brasileiras.

Palavras-chave: Serviços de referência; Publicações eletrônicas; Gestão de serviços bibliotecários; Bibliotecas universitárias; Bibliotecas eletrônicas 


\section{Introdução}

"O conhecimento é de duas espécies. Podemos conhecer nós mesmos um assunto ou saber onde encontrar informações a respeito" Grogan (200 I, p. 7), citando Samuel Johnson.

A web representa uma mudança de paradigma radical com relação aos serviços bibliotecários. Ela proporciona um ambiente informacional amplo, global, de alcance nunca visto pelos antigos serviços bibliotecários, acostumados a trabalhar num ambiente delimitado, com uma comunidade de usuários identificável, restrita e até mesmo, conhecida pessoalmente. No novo ambiente, numa escala mundial, os usuários podem ter acesso a diferentes recursos, independentes de sua localização física.

Muitos destes recursos são hoje livres, acessíveis sem cobrança de qualquer tipo de taxa. Em se falando de informações para ciência e tecnologia, uma transformação significativa dos padrões de comunicação científica está em curso, a partir do surgimento da web e das facilidades de publicação direta de resultados de pesquisa pela comunidade acadêmica (MARCONDES, 2003). A comunicação científica baseada em padrões como o periódico acadêmico, com seus mecanismos de revisão por pares, vem sendo cada vez mais questionada pela comunidade científica, que quer mais visibilidade para seus artigos, mais rapidez no ciclo de publicação e questiona a cobrança de assinaturas pelos grandes editores, que se constitui num impedimento concreto para que mais pessoas leiam os artigos. Recursos informacionais cada vez mais significativos para os usuários das bibliotecas surgem de forma independente na web, em formato digital. Seu surgimento e disseminação apontam para uma reformulação de conceitos biblioteconômicos tradicionais, como os de descrição bibliográfica, de seleção/aquisição, voltados tradicionalmente para recursos em papel que constituíam o acervo físico da biblioteca. Estas reformulações também atingem o conceito de serviços de referência.

Neste novo ambiente, as bibliotecas adquirem uma nova dimensão. Já na década de 90, Lancaster (1994, p. 9) afirmava, diante da emergência dos recursos informacionais cada vez mais acessíveis via redes, que o novo papel das bibliotecas era prover "acesso ao invés de propriedade". Os serviços de informação e bibliotecas, neste novo ambiente, adquirem uma dimensão muito mais ampla e interdependente, uma vez que, com a disponibilidade crescente de recursos informacionais acessíveis diretamente da web, as informações de interesse de seus usuários passam a ser não só os recursos internos à biblioteca, que tradicionalmente eram em papel mas, também, e de forma crescente, recursos externos, disponíveis somente na web, sejam eles gratuitos ou não. Este é o conceito da biblioteca eletrônica, também chamada de biblioteca híbrida, conforme estabelecido por Rowley (2002). Interdependência crescente é a palavra que melhor define a relação destes recursos com as bibliotecas, principalmente no tocante aos periódicos eletrônicos, bibliotecas digitais, arquivos eletrônicos ou repositórios de artigos e pre-prints eletrônicos: ao mesmo tempo em que estes recursos passam a ser demandados de forma crescente pelas respectivas comunidades de usuários, eles dependem também de avaliação, divulgação e referenciação por parte das bibliotecas. 
Até que ponto o acesso web vem alterando a forma como as bibliotecas universitárias brasileiras estão oferecendo seus serviços? Para mapear toda esta situação, esta pesquisa tem por objetivo verificar a existência de serviços oferecidos via web nos sites de bibliotecas universitárias brasileiras e identificar quais os tipos de serviços são prestados diretamente através destes sites.

\section{Referência digital: marcos conceituais}

Desde os idos de 1950, com a adoção de novas tecnologias, as bibliotecas passam por profundas mudanças. $O$ aparecimento do computador permitiu a confecção de listas bibliográficas e outras atividades de natureza gerencial e, nos meados de 1960, os países desenvolvidos já produziam bases de dados bibliográficos consultadas à distância. No entanto foi com o desenvolvimento da Internet, a partir da década de 90 do século passado, que se percebe grande avanço na área. Este desenvolvimento, segundo Briquet de Lemos ( 1998, p. 364) "possibilitou a interconexão de computadores de diferentes marcas e com diferentes sistemas operacionais, utilizando linhas telefônicas comuns combinadas com linhas de transmissão de dados de alta velocidade".

As bibliotecas começam a se transformar: nota-se uma preocupação crescente em atender o usuário com o máximo de rapidez e eficiência, maior preocupação com o acesso à informação em detrimento da posse do documento, minimizando-se as limitações de tempo e espaço na busca da informação. As coleções e os serviços foram complementados com novos formatos e novas versões, tudo isso, certamente, facilitado pela utilização das novas tecnologias.

Surgem novos tipos de biblioteca destacando-se as bibliotecas digitais, também denominadas eletrônicas ou virtuais. Ao apresentar um significado para biblioteca eletrônica, Oppenheim citado por Rowley (2002, p. 4) "descreve-a como uma coleção organizada e administrada de informação numa variedade de meios (texto, imagem fixa, imagem em movimento, som ou suas combinações), porém todos em formato digital ", organizada de tal forma que permite o acesso aos usuários reais e potenciais, através de vários mecanismos de busca, às informações disponibilizadas em rede em qualquer parte do planeta, além, é claro, das informações disponíveis na própria biblioteca.

Um outro conceito de biblioteca surge na literatura, que reflete o estado de transição de uma biblioteca que não é totalmente tradicional, apresentando, também, as características de uma biblioteca digital, considerado por Garcez e Rados (2002, p. 47), "[...] o mais adequado para satisfazer as atuais necessidades informacionais de transição pelas quais as bibliotecas convencionais vêm passando". Denominada de biblioteca híbrida, caracteriza-se por:

[...] agregar diferentes tecnologias, diferentes fontes, refletindo o estado que hoje não é completamente digital, nem completamente impresso, utilizando tecnologias disponíveis para unir, em uma só biblioteca, o melhor dos dois mundos (o impresso e o digital). 
No universo das bibliotecas acadêmicas, considerando os diferentes tipos de usuários conforme categorizados por Garcez e Rados (2002, p. 44), em "off campus, os remotos e os presentes", o acesso às fontes não convencionais, juntamente com os recursos das bibliotecas convencionais é primordial para satisfazer suas necessidades específicas de informação.

Segundo Rusbridge, citado por Garcez e Rados (2002, p. 45), as bibliotecas híbridas devem proporcionar "uma vasta gama de interfaces, incluindo diferentes tipos de formatos de informação", integrados entre si, visando tornar todos os recursos acessíveis aos usuários, em que se destacam a existência de:

- OPAC - Online Public Access Catalog - local (telnet/web);

- COPAC - Curl Online Public Access Catalog - catálogo unificado telnet/web, isto é, participação em consórcios para utilização de recursos de outras bibliotecas;

- Catálogo regional virtual unificado;

- CD-ROMs e disquetes offline;

- textos completos;

- grupos de dados remotos;

- grupos de dados locais;

- portais diversos (locais e remotos de recursos da Web;

- jornais e livros eletrônicos;

- livros e jornais impressos;

- coleções especiais, mapas, slides, gravações de áudio e vídeos.

acesso às informações nas bibliotecas híbridas se dá através de uma adequada estratégia de busca, com a utilização de descritores e cabeçalhos que representem com presteza o tema pesquisado, exigindo "conhecimento do assunto, das bases de dados e da bibliografia" (GARCEZ e RADOS, 2002, p. 50), com a ajuda do bibliotecário ou por um usuário devidamente preparado para tal.

O serviço de referência no sentido amplo, segundo Maciel e Mendonça (2000, p. 33), é aquele pertencente à função encarregada pela dinamização das coleções com atividades:

[...] engajadas no propósito final das bibliotecas, ou seja, o atendimento aos usuários reais e virtuais, a conquista dos potenciais e a decorrente dinamização do uso das coleções. [...] Compreende todas as atividades voltadas, direta e indiretamente à prestação de serviços ao usuário. Inclui a divulgação de informações gerais sobre a biblioteca [...] assim como as específicas, voltadas para um segmento específico. Promove o uso do sistema e de seus recursos e, para isso desenvolve atividades de treinamento pessoal de clientes na utilização do acervo, catálogos, bases e o acesso às bibliotecas virtuais.

O serviço de referência é uma das atividades da biblioteca que vem se beneficiando das facilidades oferecidas pela tecnologia, principalmente com o desenvolvimento da Internet e das inúmeras ferramentas que ela oferece, favorecendo, sobremaneira, a recuperação da informação. Os serviços de referência digital podem ser considerados como uma evolução dos serviços 
bibliotecários via Internet. E são, cada vez mais, praticados pelas bibliotecas, segundo Márdero Arellano (200 I). Surgiram no final da década de 80 do século passado, quando as bibliotecas começaram a disponibilizar seus catálogos na rede, o que veio facilitar a localização de documentos de uma biblioteca.

Para Ferreira (2004, p. 3), a referência digital apresenta como antecedentes a própria biblioteca tradicional com seu serviço de referência. Estudos realizados no campo da ciência da informação apontam a evolução nos serviços Ask A Services, como sendo "[...] a utilização de sites de comunidades de peritos associados numa rede digital, que respondem a questões colocadas através da Internet".

Márdero Arellano (200 I , p. 8) comenta que: "Atualmente, muitos desses serviços estão reduzidos a consultas enviadas por correio eletrônico, telefone ou formulários na WEB, consumindo tempo e exigindo um trabalho árduo de pesquisa".

Em recente pesquisa realizada nos Estados Unidos (POMERANTZ et al, 2004, p. 4), foi relatado que são poucos os modelos de referência digital cujos procedimentos se assemelham aos empregados no balcão de referência tradicional e, dentre as práticas mais utilizadas destacam-se o envio das respostas para os usuários via e-mail, e a manutenção de um formulário na web para receber as questões dos usuários. Informações obtidas nesta mesma pesquisa de Pomerantz et al (2004), citadas por Mendonça (2005, p. 236) indicam que:

Alguns serviços de referência digital armazenam as perguntas e respectivas respostas em um banco de dados de assuntos e, quando recebem uma pergunta, a base de dados é automaticamente acionada. Alguns desses serviços permitem o acompanhamento do processo registrando/informando a situação do mesmo, ou seja, se trata de uma nova questão, se recebida e ainda não respondida, se encontra em andamento. A pesquisa em base de dados das questões previamente respondidas [...] é tudo que serviços de referência digital desejam, apesar de ser importante a seleção das questões que podem ser respondidas através desta ferramenta ou, por outro lado, se referem a questões que necessitam da mediação humana para serem respondidas.

Uma das muitas ferramentas utilizadas pelos serviços de referência convencionais são as obras ou recursos de referência, como bibliografias, catálogos, guias, diretórios e bases de dados. Com o desenvolvimento da web e o surgimento de sites das bibliotecas universitárias, estas passam a poder contar com a possibilidade de, com grande facilidade, incorporar em seus sites um conjunto de links para recursos web de interesse dos seus usuários.

Tudo indica que as bibliotecas, principalmente as universitárias, passarão a adotar, cada vez mais, serviços via web. Mendonça (2005, p. 240), acredita que

a tendência atual é que a oferta dos serviços de referência digital se amplie nas bibliotecas e que se instalem serviços que funcionem em tempo real, utilizando-se dos chats e das mensagens instantâneas, entre outros recursos que a tecnologia possa oferecer. 


\section{A pesquisa}

Nesta pesquisa foram visitados sites de bibliotecas universitárias brasileiras, procurando identificar a existência dos diversos serviços oferecidos via web. Entre os diferentes tipos de serviços prestados objetivava-se identificar, especialmente: a) o serviço de referência no seu sentido tradicional e entendido como todo e qualquer apoio ao uso de recursos da biblioteca e a indicação de fontes, oferecidos via web; b) a existência de portais web construídos pelas bibliotecas, entendidos com uma coleção de recursos web, externos à coleção da biblioteca, mas reunidos, avaliados, categorizados e disponibilizados como fontes adicionais ao acervo para seus usuários.

Como critério para a seleção dos sites foram consideradas as bibliotecas das 7 (sete) primeiras IES das 5 (cinco) regiões do país com maior número de cursos de pós-graduação, segundo consta na lista de mestrados/doutorados reconhecidos pela CAPES (http:// www.capes.gov.br). Em cada uma destas IES foram visitados os sites existentes de todas as suas bibliotecas, sejam elas centrais ou setoriais. Os dados identificados nos sites de cada biblioteca visitada foram registrados num formulário padronizado. As visitas aos sites ocorreram entre agosto de 2004 e abril de 2005. Foram analisados sites de 209 bibliotecas de todas as regiões do país.

\section{Resultados: apresentação e análise}

Serão apresentados e analisados os dados referentes a: natureza das IES (TAB. I), categorização das bibliotecas (TAB. 2), nível de especificidade do site da biblioteca (TAB. 3), serviço de referência considerados típicos (TAB. 4), portais de recursos na web (TAB. 5), serviços de referência considerados públicos (TAB. 6).

TABELA I - Natureza das IES

\begin{tabular}{l|c|c|c|c|c|c}
\hline Natureza IES & Federais & Estaduais & Municipais & Confessionais & Particulares & Total Bibliotecas \\
\hline Regiões & $N^{\circ}$ & $N^{\circ}$ & $N^{\circ}$ & $N^{\circ}$ & $N^{\circ}$ & $N^{\circ}$ \\
\hline Total & 128 & 71 & 0 & 6 & 4 & 209 \\
\hline Sudeste & 57 & 68 & 0 & 0 & 0 & 125 \\
\hline Sul & 38 & 3 & 0 & 6 & 0 & 47 \\
\hline Nordeste & 26 & 0 & 0 & 0 & 0 & 26 \\
\hline Centro Oeste & 4 & 0 & 0 & 0 & 3 & 7 \\
\hline Norte & 3 & 0 & 0 & 0 & 1 & 4 \\
\hline
\end{tabular}

Da análise dos sites de 209 bibliotecas das cinco regiões do país, constatou-se que 128 são de IES federais, 7I estaduais, 0 (zero) municipais, 6 confessionais e 4 particulares. 
TABELA 2 - Categorização das Bibliotecas

\begin{tabular}{l|c|c|c}
\hline Tipo Biblioteca & \multicolumn{1}{c}{ Centrais } & Setoriais & Total Bibliotecas \\
\hline Regiões & $\mathrm{N}^{\circ}$ & $\mathrm{N}^{\circ}$ & $\mathrm{N}^{\circ}$ \\
\hline Total & 32 & 177 & 209 \\
\hline Sudeste & 7 & 118 & 125 \\
\hline Sul & 7 & 40 & 47 \\
\hline Nordeste & 7 & 19 & 26 \\
\hline Centro Oeste & 7 & 0 & 7 \\
\hline Norte & 4 & 0 & 4 \\
\hline
\end{tabular}

Entre os sites de bibliotecas visitados, 32 (trinta e dois) eram de bibliotecas centrais e 177 (cento e setenta e sete) de setoriais. A TAB. 2 mostra estes resultados por região. Foram identificadas as bibliotecas centrais e respectivas setoriais de cada uma das sete IES, das cinco regiões do país. $O$ maior número de setoriais com homepages próprias encontra-se na região Sudeste onde, das 136 bibliotecas setoriais existentes das sete IES, I I 8 tinham sites. Na região Sul foram encontrados 40 sites de bibliotecas setoriais, nas 74 bibliotecas setoriais existentes nas sete IES da região. Na região Nordeste, das 76 bibliotecas setoriais existentes nos sistemas de bibliotecas das 7 universidades, apenas 19 tinham sites. Na região Centro-Oeste e Norte as bibliotecas setoriais não tinham sites. Na região Norte apenas as bibliotecas centrais das quatro IES têm sites.

TABELA 3 - Nível de especificidade do site da biblioteca

\begin{tabular}{l|c|c|c|c}
\hline $\begin{array}{l}\text { Especialização } \\
\text { Biblioteca }\end{array}$ & Geral & $\begin{array}{c}\text { Especializado } \\
\text { (somentel tipo de recurso) }\end{array}$ & $\begin{array}{c}\text { Multi-especializado } \\
\text { (vários tipos de recursos) }\end{array}$ & $\begin{array}{c}\text { Total } \\
\text { (Biblioteca) }\end{array}$ \\
\hline Total & 32 & 42 & 135 & 209 \\
\hline Sudeste & 15 & 22 & 88 & 125 \\
\hline Sul & 9 & 9 & 29 & 47 \\
\hline Nordeste & 6 & 6 & 10 & 26 \\
\hline Centro- Oeste & 2 & 0 & 5 & 7 \\
\hline Norte & 0 & 1 & 3 & 4 \\
\hline
\end{tabular}

A TAB. 3 indica o nível de especificidade do site da biblioteca com relação aos recursos disponibilizados via web, onde o nível geral indica as bibliotecas com homepages simples, isto é, com informações da própria biblioteca como acervo, serviços, equipe e histórico, sem apresentarem links para recursos externos à biblioteca. As bibliotecas classificadas neste nível são em menor número nas cinco regiões do país. Já o nível especializado indica os sites das bibliotecas com links para apenas um tipo de recurso externo. Estes tipos de recursos podem ser observados na TAB. 4, e são ou periódicos eletrônicos, ou bases de dados e bibliotecas virtuais, ou informações utilitárias, ou os portais públicos, como Capes e Scielo. A região que apresenta maior número de bibliotecas com esta característica é a Sudeste, com 22 (vinte e 
duas) indicações, seguida pela região Sul, com 9 (nove) indicações, a região Nordeste com 6 (seis) indicações e a Norte com I (uma). A região Centrooeste não apresenta bibliotecas com esta característica. Enquanto o nível multiespecializado indica os sites que contém links para mais de um tipo de recurso externo, além dos portais públicos. Este último nível é o mais representativo nas cinco regiões do país.

TABELA 4 - Serviços de referência considerados típicos

\begin{tabular}{|c|c|c|c|c|c|c|c|c|c|c|c|}
\hline $\begin{array}{l}\text { Serviços } \\
\text { Referência. } \\
\text { Típicos }\end{array}$ & $\begin{array}{l}\text { Per } \\
\text { resp } \\
\text { bibl }\end{array}$ & $\begin{array}{l}\text { Inta- } \\
\text { sta à } \\
\text { teca }\end{array}$ & $\begin{array}{r}\text { Nor } \\
\text { Elabo } \\
\text { cat }\end{array}$ & $\begin{array}{l}\text { ização/ } \\
\text { lo. fichas } \\
\text { ráficas }\end{array}$ & $\begin{array}{r}\text { Leva } \\
\text { bib }\end{array}$ & $\begin{array}{l}\text { amento } \\
\text { gráfico }\end{array}$ & & $\begin{array}{l}\text { ários } \\
\text { entes } \\
\text { ine }\end{array}$ & $\begin{array}{r}\text { Cat } \\
\text { Or }\end{array}$ & $\begin{array}{l}\text { álogo } \\
\text { line }\end{array}$ & Total Bibliotecas \\
\hline Regiões & $\mathrm{N}$ & $\%$ & $\mathrm{~N}$ & $\%$ & $\mathrm{~N}$ & $\%$ & $\mathrm{~N}$ & $\%$ & $\mathrm{~N}$ & $\%$ & $\mathrm{~N}$ \\
\hline Total & 7 & 3,35 & 19 & 9,09 & 19 & 9,09 & 21 & 10,05 & 173 & 82,77 & 209 \\
\hline Sudeste & 4 & 3,20 & 16 & 12,80 & 12 & 9,60 & 15 & 12,00 & 40 & 32,00 & 125 \\
\hline Sul & 3 & 6,38 & I & 2,13 & 5 & 10,63 & 6 & 12,76 & 37 & 78,73 & 47 \\
\hline Nordeste & 0 & 0,00 & 0 & 0,00 & 0 & 0,00 & 0 & 0,00 & 21 & 80,77 & 26 \\
\hline Centro Oeste & 0 & 0,00 & । & 14,28 & । & 14,28 & 0 & 0,00 & 6 & 85,71 & 7 \\
\hline Norte & 0 & 0,00 & | & 25,00 & | & 25,00 & 0 & 0,00 & 4 & 100,00 & 4 \\
\hline
\end{tabular}

Esta tabela indica os tipos de serviço de referência, considerados como típicos, encontrados nas bibliotecas observadas. O serviço do tipo perguntaresposta é o que mais se assemelha aos serviços do tipo Ask-A existentes no exterior, onde os usuários podem fazer perguntas à biblioteca através de email ou formulários próprios e receber as repostas também pela web. Somente quatro ou 3,2\% das bibliotecas na região Sudeste e três ou 6,38\% das bibliotecas na região Sul oferecem este primeiro serviço. No entanto, observou-se que este serviço se assemelha aos oferecidos no exterior apenas no formato (pergunta via e-mail), pois, quanto ao conteúdo das perguntas, estas se referem a informações da própria biblioteca (por exemplo, sobre o acervo). O serviço normalização de trabalhos e elaboração de fichas catalográficas para monografias, dissertações e teses são oferecidos em 16 (dezesseis) bibliotecas da região Sudeste, representando I2,8\% das bibliotecas visitadas e em I (uma) biblioteca das regiões Sul (2, I 3\%), Centro-oeste (14,28\%) e Norte (25\%). Para oferecer o serviço elaboração de ficha catalográfica via Web, as 19 bibliotecas (9\% do total das bibliotecas pesquisadas) que oferecem o serviço solicitam ao usuário que digite os dados a serem colocados na ficha, em formulários web ou e-mail e envie à biblioteca para que os bibliotecários possam elaborar estas fichas. $\bigcirc$ serviço levantamento bibliográfico, onde a biblioteca envia por e-mail ao usuário, o resultado da pesquisa bibliográfica sobre o assunto de seu interesse é oferecido em 19 (dezenove) bibliotecas do país (9\%), distribuídas em 12 (doze) bibliotecas (9\%) na região Sudeste, 5 (cinco) na região Sul ( I0,6\%), I (uma) biblioteca na região Centro-oeste (I4,2\%) e I (uma) biblioteca na região Norte (25\%). O serviço de disponibilização de sumários correntes online só é oferecido em 15 (quinze) bibliotecas da região Sudeste (I2\%) e em 6 (seis) bibliotecas da região Sul (I2,7\%). A disponiblização do catálogo online via Web é o tipo de serviço mais disseminado, atingindo $82,7 \%$ do total das 
bibliotecas visitadas, apresentando grandes percentuais em todas as regiões. Isso pode ser explicado pelo alto grau de informatização dos sistemas das bibliotecas analisadas. $O$ catálogo online é um subproduto mais comum dos modernos sistemas de automação de bibliotecas, não requerendo qualquer esforço adicional que a inclusão de registros nos sistemas.

TABELA 5 - Portais de Recursos na WEB

\begin{tabular}{l|c|c|c}
\hline Portais de Recursos Web & Total Serviços & Total Bibliotecas & Percentual \\
\hline Total & 9 & 209 & $4,31 \%$ \\
\hline Sudeste & 7 & 125 & $5,60 \%$ \\
\hline Sul & 1 & 47 & $2,13 \%$ \\
\hline Noerdeste & 0 & 26 & $0,00 \%$ \\
\hline Centro-Oeste & 1 & 7 & $14,28 \%$ \\
\hline Norte & 0 & 4 & $0,00 \%$ \\
\hline
\end{tabular}

Os portais construídos pelas bibliotecas, como uma coleção de recursos web externos à coleção, mas reunidos, avaliados, categorizados e disponibilizados como fontes adicionais ao acervo para seus usuários só são observados em 9 (nove) bibliotecas centrais no Brasil: 4 (quatro) em São Paulo, 2 (duas) no Rio de Janeiro, I (uma) em Minas Gerais, I (uma) no Rio Grande do Sul e I (uma) no Distrito Federal. Pelas suas características inovadoras estes portais são descritos a seguir:

- UFF - Universidade Federal Fluminense: A UFF tem um portal de referência nas áreas de arquivologia, biblioteconomia e ciência da informação (<http://www.ndc.uff.br/portaldereferencia/default.asp > ). Este portal conta com um diretório de notícias sobre as três áreas acima, programação de eventos, links para escolas, instituições, publicações, produtos e serviços, museus, arquivos e bibliotecas, entre outros. Tem um mecanismo de busca ao portal e às perguntas mais freqüentes respondidas pela equipe, além de formulários para receber as perguntas dos usuários. Envia newsletter aos usuários cadastrados com as novidades incluídas no portal.

- USP - Universidade de São Paulo: O Sistema de Bibliotecas da USP (http://www.usp.br/sibi), na seção Bibliotecas Virtuais, criou o serviço Revistas Eletrônicas. Nesta seção encontra-se uma listagem das revistas assinadas pela universidade, organizadas em ordem alfabética. A equipe do SiBi disponibilizou, ainda, um tutorial ensinando aos usuários como acessar e pesquisar nas revistas, como se cadastrar junto às editoras para receberem alertas eletrônicos de novos fascículos, das revistas de sua preferência.

- UNICAMP- Universidade Estadual de Campinas: A Biblioteca Central da UNICAMP (http://www.unicamp.br/bc/) também criou uma seção para organizar as revistas disponíveis online, intitulada Periódicos Eletrônicos. Os títulos são organizados por ordem alfabética e também 
por bibliotecas do sistema. A lista inclui tanto títulos assinados pela Unicamp, quanto títulos gratuitos ou disponíveis na Capes. Junto a cada título encontra-se o fornecedor do acesso online e a biblioteca que possui a coleção impressa. Explica ao usuário como obter autorização para acesso às revistas, disponibiliza um e-mail para receber dúvidas dos usuários e para resolver problemas para o acesso aos títulos, além de apresentar as estatísticas de uso do portal.

- UNIFESP - Universidade Federal de São Paulo: A Biblioteca Central da UNIFESP (http://www.biblioteca.epm.br) criou a seção Portal de Revistas da UNIFESP que usa a mesma interface usada pela Biblioteca Virtual em Saúde / Bireme, organizando os títulos por ordem alfabética e por especialidades médicas, além de destacar links para outros portais de periódicos e para as bibliotecas virtuais temáticas da BVS/Bireme. Junto a cada título encontram-se informações editoriais sobre o periódico, links para o formato eletrônico e para o nome e endereço das bibliotecas que possuem o título em suas coleções.

- UFMG - Universidade Federal de Minas Gerais: A Biblioteca de Enfermagem da UFMG (http://www.bvs.enf.ufmg.br/html/pt/home.html) também usa a interface da Biblioteca Virtual em Saúde/Bireme. O portal lista os eventos da área, fontes de referência e outras fontes complementares.

- UNB - Universidade de Brasília: A Biblioteca Central da UNB (http://www.bce.unb.br) disponibiliza, na seção Acervo, uma listagem dos títulos de periódicos estrangeiros, com os links organizados por faculdades e por institutos da universidade.

- $\quad$ PUC-RS - Pontifícia Universidade Católica do Rio Grande do Sul: O portal da PUC-RS (http://www. pucrs.br/biblioteca) lista na seção Recursos Online bases de dados, jornais e periódicos eletrônicos, teses online entre outras fontes. Possui um mecanismo de busca por palavras e por áreas do conhecimento. Sob cada registro encontra-se a avaliação feita pela equipe da biblioteca, informando o tipo de acesso e os assuntos cobertos por cada recurso.

TABELA 6 - Serviços de referência considerados públicos

\begin{tabular}{|c|c|c|c|c|c|c|c|c|c|c|c|c|c|}
\hline \multirow[t]{2}{*}{$\begin{array}{l}\text { Serviços Referência } \\
\text { "Públicos" }\end{array}$} & \multicolumn{2}{|c|}{ SciELO } & \multicolumn{2}{|c|}{ Probe } & \multicolumn{2}{|c|}{$\begin{array}{l}\text { Portal } \\
\text { CAPES }\end{array}$} & \multicolumn{2}{|c|}{ BDTD } & \multicolumn{2}{|c|}{ PROSSIGA } & \multicolumn{2}{|c|}{$\mathrm{CCN}$} & \multirow{2}{*}{$\begin{array}{c}\text { Total } \\
\text { Bibliotecas }\end{array}$} \\
\hline & $N^{\circ}$ & $\%$ & $N^{\circ}$ & $\%$ & $N^{\circ}$ & $\%$ & $N^{\circ}$ & $\%$ & $N^{\circ}$ & $\%$ & $N^{\circ}$ & $\%$ & \\
\hline Total & 97 & 46,41 & 36 & 17,22 & 133 & 63,63 & 53 & 25,35 & 94 & 44,97 & 73 & 34,93 & 209 \\
\hline Sudeste & 67 & 53,60 & 34 & 27,20 & 85 & 68,00 & 32 & 25,60 & 51 & 40,80 & 50 & 40,00 & 125 \\
\hline Sul & 14 & 29,78 & 2 & 4,25 & 30 & 63,83 & 16 & 34,04 & 28 & 59,57 & 16 & 34,04 & 47 \\
\hline Nordeste & 10 & 38,47 & 0 & 0,00 & 10 & 38,47 & 3 & $1 \mid, 54$ & 10 & 38,47 & 5 & 19,23 & 26 \\
\hline Centro- Oeste & 4 & 57,14 & 0 & 0,00 & 5 & 71,42 & 0 & 0,00 & 3 & 42,85 & 0 & 0,00 & 7 \\
\hline Norte & 2 & 50,00 & 0 & 0,00 & 3 & 75,00 & 2 & 50,00 & 2 & 50,00 & 2 & 50,00 & 4 \\
\hline
\end{tabular}


A tabela acima indica a quantidade de bibliotecas, sem distinção entre centrais e setoriais, que referenciam os serviços públicos, como SciELO, Probe, Portal de Periódicos Capes, Base de Dados de Teses e Dissertações do IBICT - BDTD, Portal de Bibliotecas Virtuais Temáticas do Prossiga e o Catálogo Coletivo Nacional do IBICT. O Portal CAPES é o serviço mais referenciado pelas bibliotecas universitárias brasileiras pesquisadas, atingindo um percentual de $63,63 \%$, seguido pelo SciELO, com 46,41\%. O PROSSIGA alcançou $44,97 \%$, o CCN 34,93\%, a BDTD 25,35\% e o Probe 17,22\%.

\section{Conclusões}

Os serviços oferecidos pelas bibliotecas universitárias de forma remota são ainda muito restritos. O mais amplamente encontrado é a disponibilização do catálogo via Web, que é um subproduto dos sistemas de automação de bibliotecas, já implantados na maioria das bibliotecas universitárias brasileiras.

Os serviços mais diferenciados, como pergunta/resposta à biblioteca, normalização, levantamento bibliográfico, sumários correntes (este também, muitas vezes é um subproduto dos sistemas de automação de bibliotecas) são em menor número e se concentram nas regiões Sudeste e Sul; a região Sul, embora tenha menos serviços, percentualmente tem mais que a região Sudeste.

$\bigcirc$ que foi aqui tratado como serviços de referência típicos aparecem, em maior número que os portais, outro foco de atenção desta pesquisa mas, ainda assim, são muito precários, como no caso do serviço tipo pergunte à biblioteca, restringindo-se a tirar dúvidas do usuário sobre o acervo da biblioteca, seus serviços etc. Não existem serviços do tipo ASK Librarian, como utilizados no exterior, entre os serviços de referência típicos.

Apesar dos portais serem ainda poucos, são os serviços mais elaborados. No entanto, constata-se que a montagem de um portal é dispendiosa, difícil e trabalhosa para ser desenvolvida por uma só biblioteca. Há a necessidade de permanente manutenção para evitar links desatualizados. No entanto, portais são serviços cada vez mais úteis para indicar informação de qualidade, avaliada e organizada sistematicamente, evitando que o usuário perca tempo procurando informações a esmo na web.

A criação de um programa de portais temáticos públicos, a exemplo do programa inglês SOSIG (www.sosig.ac.uk) seria uma solução, que resultaria em serviços de melhor qualidade, desenvolvidos cooperativamente por várias bibliotecas, de acordo com os interesses de seus usuários. Duas iniciativas neste sentido já existem aqui no Brasil. A primeira são as bibliotecas virtuais, coordenadas pela BIREME; no entanto, esta iniciativa tem uma abrangência temática restrita às ciências da saúde. A segunda é o Programa PROSSIGA, o qual, no entanto, não trabalha com a concepção de portais cooperativos, desenvolvidos e mantidos por várias instituições.

As publicações eletrônicas são uma realidade. Elas passam a ser consideradas, de forma crescente nas políticas de desenvolvimento de acervo das bibliotecas. Cada vez mais as bibliotecas se tornam bibliotecas híbridas, aquelas que em seu catálogo referenciam tanto recursos impressos quanto recursos eletrônicos. Seguindo uma tendência inaugurada com publicações eletrônicas experimentais, os grandes editores passaram a disponibilizar, também, versões eletrônicas de suas publicações em papel e disponibilizá-las com portais como ScienceDirect, Sirus etc. Hoje, lado a 
lado com publicações em texto completo destes editores, as bibliotecas têm a opção de acessar portais gratuitos como o SciELO, DOAJ, Open Medical Journal, JSTOR etc.

A forma como as bibliotecas convencionais passaram a oferecer estes recursos se inicia simplesmente com um link para o recurso a partir da página da biblioteca. A maioria das páginas de bibliotecas brasileiras, hoje, exibe links para recursos eletrônicos, gratuitos ou não. Esta forma simples de referenciar os crescentes recursos eletrônicos, logo se sofistica. $O$ formato MARC passa a incorporar recentemente o parágrafo 856 - Localização e acesso eletrônico para permitir a inclusão de recursos eletrônicos e seu referenciamento a partir do catálogo das bibliotecas, juntamente com outros recursos impressos.

O parágrafo 856 do MARC é uma opção qualitativamente superior de referenciar recursos eletrônicos que a simples inclusão de links na página da biblioteca. Isso porque o usuário busca e acessa um recurso eletrônico como faz com qualquer outro recurso, a partir da interface de busca do catálogo da biblioteca, do OPAC. Isto evita que o usuário tenha que acessar e realizar sua busca acessando as diferentes interfaces web de cada um dos diferentes recursos referenciados, o que poderia gerar dificuldades para que o usuário acessasse a informação desejada.

No entanto, esta alternativa ainda não é de todo satisfatória. Os links se constituem na parte mais vulnerável do acesso a recursos eletrônicos. São frustrantes para os usuários as mensagens do browser de página não disponível. Ou, muitas vezes, o usuário encontra um recurso para o qual precisa de autorização, para o qual é necessária uma assinatura eletrônica.

Para minimizar estes casos foi proposto o conceito de serviços expandidos (WALKER, 2005) que consiste num servidor de links contextuais da biblioteca, hospedado em seu próprio servidor ou no servidor de um prestador destes serviços. O servidor de links contextuais resolve, da melhor maneira possível, no contexto dos recursos e serviços disponíveis na biblioteca, os links acionados a partir do OPAC. Por exemplo, remetendo o usuário para um formulário de solicitação de cópia em papel a partir da coleção da biblioteca ou para uma cópia alternativa num repositório eletrônico aberto.

Enfim, a biblioteca trabalha configurando e administrando o servidor de links contextuais para otimizar, com seus próprios recursos, as possibilidades de acesso a recursos eletrônicos referenciados no seu catálogo. O servidor de links contextuais é um elemento chave para a gestão dos recursos eletrônicos de uma biblioteca. Estes links seguem um padrão emergente denominado OpenURL (VAN DE SOMPEL 1999a e 1999b), que contem, além do link propriamente dito, mais um conjunto de informações que permitem ao servidor de links contextuais resolver cada link da melhor maneira possível para as condições da biblioteca. Este padrão se tornou o protocolo NISO Z39.88.

Constata-se, assim, que a maioria das bibliotecas universitárias ainda não iniciou a transição de seus serviços rumo à biblioteca híbrida. A forma mais sofisticada destes serviços são os portais desenvolvidos ainda por poucas bibliotecas universitárias. A maioria ainda trabalha pouco com a crescente quantidade de recursos informacionais disponíveis via Web, cuja importância, relativamente aos acervos locais das bibliotecas, tende a crescer cada vez mais. 


\section{Web delivery services in Brazilian University Libraries}

Reports results of PIBIC CNPq/UFF funded research developed from August/2004 to July/2005, which aims to identify Web services offered by Brazilian university libraries. 209 web sites of university libraries from all regions were evaluated, chosen from the first seven universities of each region with greater number of Master and Phd programs, according to CAPES. The web sites of those libraries were visited and surveyed in order to identify which services were offered via Web. We concluded that Brazilian university libraries offer few of this kind of services.

Key-words: Digital reference services; Electronic publishing; Library services management; University libraries; Electronic libraries

\section{Referências}

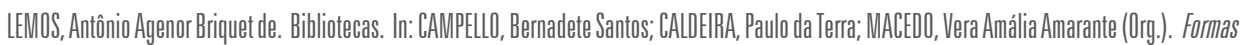

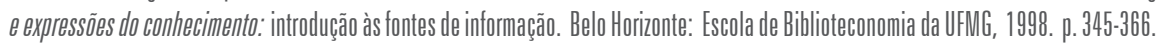

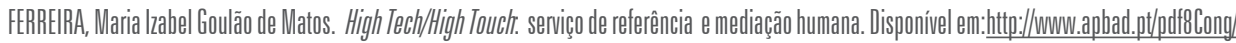
com/com29.pdf. Acesso em 27 set. 2004.

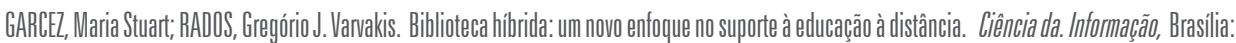
v. 31, n. 2, p. 44-51, maio/ago. 2002.

GROGAN, Denis. A prática do senviço de refereência. Brasilia: Briquet de Lemos/Livos, 2001.

HUTCHIIIS, Margaret. Introduçãa ao trabablho de referênncia em biblliotecas. Rio de Janeiro: FGV, 1973.

LAWCASTER, Frederic Winfed. Ameaça ou oportunidade? O futuro dos senviços de bibliotecas à luz das inovaç̣oes tecnologicicas. Revista da Escola de Biblioteconomia da UFMG, v. 25, n. 1, p. . .27, jan.jJun. 1994.

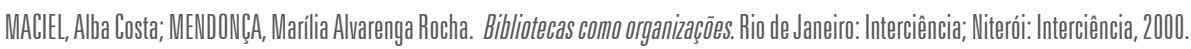

MARCONDES, Carlos Henriquu; SAYĀo, Luis Fernando. Documentos digitais e novas formas de cooperaçāa entre sistemas de informaçãa em CGy. Ciênncia da

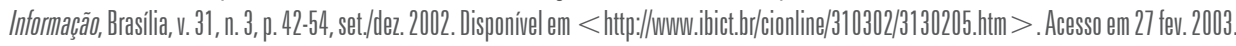

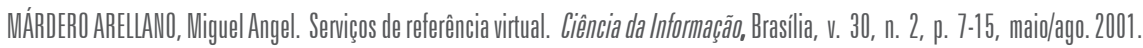

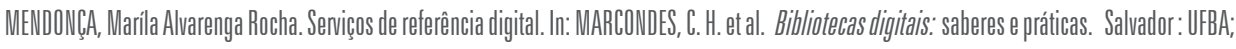
Brasilia: Ibict, 2005. p.227-240.

IHEOPENUURL Frameworkffor Context-sensitive Services. ANS//NISOZ39.88-2004.

POMERANIZ, Jeffrey etal. The current state of digital reference:. validation of a general ligital reference model through a sunvey of digital referennce senvices.

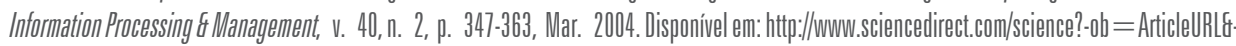
udi=BbUC8-47PPGDR-14-coverDate. Acesso em 13 nov. 2004.

ROWLEY, Jennifer. Abiblioteca eletrônica. Brasilia: Briquet de Lemos/livros, 2002.

VAN DE SOMPFL, Herbert; HOCHSTEWBACH, Patrick. Refererence linking in a hybrid library environment. Part 1: framework for linking. D.-Lib Magazine, v. 5, n. 4, Apr. 1999. Disponivel em < httpp///wwwdlib.org/dlib/april99//van de somple-pt1. html > . Acesso em 21 jun. 2005.

VAN DE SOMPEL, Herbert; HOCHSTENBACH, Patrick. Reference linking in a hybrid librany enuironment. Part2: SFX, a generic linking solution. D-Lib Magazine, v. 5, n. 4. App. 1999. Disponivel em < http://wwwdlib.org/dib/aprilg9/van_de_somple-pt2.html > . Acesso em 21 jun. 2005.

WAALER, Jenny. Waht is SFX? Learned Publishing, v. 14, n. 4, p. 296-299, Oct. 2005 